\title{
Perspectiva jurídica de la relación entre farmacoterapia antidepresiva y suicidio
}

RESUMEN: Análisis de la responsabilidad derivada de los daños propios o a terceros que tienen su origen en el tratamiento farmacológico con antidepresivos.

PALABRAS CLAVE: Responsabilidad. Suicidio. Antidepresivos.

\begin{abstract}
Analysis of the derived liability of the own damages or at third that have their origin in the pharmacological treatment with antidepressants.
\end{abstract}

KEY WORDS: Liability. Suicide. Antidepressants.

\section{Planteamiento del tema.}

En términos generales, los médicos prescriben con razonable acierto (1), las empresas farmacéuticas crean productos con encomiables resultados y los Estados controlan la salud pública con creciente eficacia. Y sin embargo, voy a hablar aquí de un producto (los fármacos antidepresivos), producido por empresas punteras en el campo de la investigación (las empresas farmacéuticas) que al ser aplicados generan, en ocasiones, consecuencias tan infrecuentes como dramáticas (homicidios y suicidios).

No voy a ser yo quien rompa una lanza a favor o en contra de la seguridad de estos fármacos. Me falta formación para ello. Pero sí me atrevo a describir una panorámica general de los aspectos jurídicos del tema. No tengo ningún ánimo de exhaustividad, ni tampoco un breve artículo sería cauce adecuado para ello. Pero no me resisto a dejar de plasmar en trazos gruesos un boceto del conjunto de responsabilidades que pueden derivarse de la actuación homicida-suicida de un paciente en tratamiento con fármacos antidepresivos. El momento parece el indicado a la vista de noticias que estos últimos días nos han llegado del otro lado del Atlántico (2), por lo que dedicaré especial atención a la responsabilidad empresarial.

Bajo ningún concepto pretendo ser alarmista. Estamos a años luz del conjunto de intereses que giran en torno a las millonarias demandas de responsabilidad en EE.UU., que incluso ganadas, frecuentemente reportan escasos beneficios a los propios pacientes. Me interesa, muy especialmente, aprovechar la ocasión para sentar las bases de una reflexión compartida. Creo que hace falta. La espectacularidad de los casos de que aquí se trata, unida a la fácil tentación demagógica pueden ocultar otras deficiencias del sistema. Ya que si exigible es que las empresas farmacéuticas informen de los niveles de seguridad, reacciones y efectos indeseados de sus productos, no menos exigible es que la Administración "administre", que el facultativo conozca sus propias "facultades" y que el investigador coadyuve a mejorar la eficacia de los productos, no solo indagando sino también informando de los resultados de su indagación.

De todo ello se tratará a continuación. 


\section{Las diferentes caras de la responsabilidad.}

\subsection{Responsabilidad personal.}

Cuando el médico se encuentra ante un cuadro depresivo es común que, además de cualquier otro tipo de terapia que considere pertinente, prescriba un determinado fármaco. Y es aquí, precisamente donde puede radicar una fuente de responsabilidad profesional. La impericia, se afirma en las Instituciones de Justiniano (IV, 3, 7) es también culpa y acontece tanto cuando "un médico mata al operar mal a un esclavo, como cuando le prescribe un medicamento inadecuado". La impericia, tal como aquí es entendida (como carencia de peritia artis) puede dar origen a diferentes manifestaciones de la responsabilidad (3):

- la deontológica, que tiene lugar cuando el médico quebranta su deber de abstenerse de actuaciones que sobrepasen su capacidad (art. 19.1 Código de Ética y Deontología Médica, 10.9.1999) (4).

- la civil, ya que la falta de preparación técnica es culpable y es, en consecuencia, fundamento de la responsabilidad (5).

- la penal, pues la incompetencia profesional puede comportar una imprudencia punible, considerada esta como "la innecesaria puesta en peligro de los bienes jurídicos ajenos" (6).

- la administrativa en vía de regreso, cuando siendo empleado público la Administración haya indemnizado los daños originados por su conducta gravemente dolosa, culposa o negligente (art. 145.2 LRJPAC, en redacción dada por Ley 4/1999, 13 enero).

Pues bien, todas las precedentes manifestaciones de responsabilidad derivadas de la impericia son teóricamente aplicables cuando de prescripción de antidepresivos se trata. Piénsese en el uso inapropiado de antidepresivos cuando no exista indicación terapéutica o la falta de seguimiento de sus efectos; imagínese la prescripción sin tener en cuenta las interacciones advertidas o la ausencia de toda consideración temporal de los efectos del fármaco; y, en lo que aquí interesa, medítese acerca de las consecuencias graves e indeseables divulgadas prolijamente por la literatura científica, como luego se verá. El largo elenco de fármacos que se distribuyen en la actualidad y el frecuentemente complejo manejo de los mismos, abogaría -en principio- por la prescripción de los mismos a cargo de especialistas, lo cual en absoluto desmerece la labor de los médicos de atención primaria que, en este punto, han de saber conjugar su criterio clínico (elaborando un diagnóstico provisional, cuando ello sea posible), su labor gestora (derivando pacientes a quien proceda), su actuación impostergable (instaurando el tratamiento de urgencia que la situación demande) y una considerable dosis de prudencia.

No seré yo quien haga propias las palabras de Cervantes, "sólo los médicos nos pueden matar, y nos matan sin temor y a pie quedo, sin desenvainar otra espada que la de un récipe"(7), pero creo que sí puede compartirse que una prescripción inadecuada puede desencadenar efectos incluso irremediables y arrostrar dramáticas consecuencias profesionales. 


\subsection{Responsabilidad empresarial.}

Cuando empleo aquí el término "responsabilidad empresarial", me estoy refiriendo a la responsabilidad propia de las empresas farmacéuticas, pues la incidencia de la responsabilidad hospitalaria solo indirectamente interesaría (8).

Tradicionalmente, la responsabilidad de estas empresas puede derivar de la siguiente tipología de defectos: de fabricación en sentido estricto, de construcción y de instrucción e información (9). Esta tipología será la que se siga en la Restatement (Third) of Torts: Products Liability (1997) del American Law Institute (10), norma que sustituyó a la sección 402A de la Restatement (Second), que se había configurado a partir de 1965 como el modelo de referencia de las legislaciones estatales y standard de obligada cita en las sedes judiciales. Y una de las novedades principales de la nueva regulación será, precisamente, la diferenciación de dos tipos de sistemas de responsabilidad:

- para los defectos de producción (fabricación) la responsabilidad es objetiva (strict liability).

- para los defectos de diseño y para las defectuosas instrucciones o advertencias, la responsabilidad es subjetiva, es decir ha de concurrir un comportamiento culposo por parte de la compañía. Se tienen en cuenta, en definitiva, la previsibilidad (foreseeability) y la razonabilidad (reasonableness) de las decisiones empresariales (11).

Como luego veremos, en el caso de los fármacos antidepresivos el mayor interés radica en los defectos de diseño y, sobre todo, en la inadecuación de las instrucciones y advertencias -en relación precisamente con el riesgo homicida-suicida. No dedicaremos una autónoma atención al defecto de diseño por dos razones: 1) carece de tratamiento autónomo en España y 2) en la práctica aparece unido de forma más o menos directa con la defectuosa información, como pronto constataremos. Baste dejar ya anunciado que el tratamiento en sede de responsabilidad es diferente en Estados Unidos que en España. En Estados Unidos el defecto de diseño y la inadecuada información requieren un componente culpabilístico; en España, por el contrario, el sistema es netamente objetivo para todos los supuestos de productos defectuosos.

\subsection{Responsabilidad Administrativa.}

Compete a la Administración pública ejercer la labor de vigilancia e inspección sobre los productos farmacéuticos de uso humano. Y ello tanto en la fase previa (de autorización del producto) como en la posterior (de comercialización).

a) Fase de autorización. El Reglamento (CEE) núm. 2309/93 del Consejo, de 22 de julio de 1993, por el que se establecen procedimientos comunitarios para la autorización y supervisión de medicamentos de uso humano y veterinario y por el que se crea la Agencia Europea para la Evaluación de Medicamentos (DOCE L 214/1993 de 24-08-1993), establece la preceptividad en las solicitudes de autorización de un medicamento para uso humano de los datos y documentos a que hacen referencia los arts. 4 y 4 bis de la Directiva 65/65/CEE, el Anexo de la Directiva 75/318/CEE y el art. 2 de la Directiva 75/319/CEE (art. 6). Es más, "se denegará la autorización cuando la 
información y los documentos presentados por el solicitante con arreglo al art. 6 sean incorrectos o cuando las etiquetas o prospectos propuestos por el solicitante no se ajusten a lo dispuesto en la Directiva 92/27/CEE” (art. 11.II), existiendo, por lo demás, obligación por parte del responsable de la comercialización de participar a la Agencia y a la Comisión y comunicar a los Estados miembros -sin demora- cualquier modificación en la información del producto "que pueda influir en la evaluación de las ventajas y riesgos del medicamento de que se trate" (art. 15.2). Este Reglamento contempla, asimismo, un control por parte de la Agencia de la información sobre reacciones adversas de los medicamentos (art. 20).

A nivel español recae sobre la Agencia de Medicamento, cuyo Estatuto fue aprobado por Real Decreto 520/1999, 26 marzo (BOE, 31 marzo) la autorización de las especialidades farmacéuticas de uso humano. El control administrativo, en este momento previo a la distribución y comercialización tiene varias manifestaciones:

- El art. 5 del Estatuto citado encomienda a la Agencia las tareas las tareas de concesión, denegación, modificación, restricción, suspensión o revocación de autorizaciones de comercialización de especialidades farmacéuticas de uso humano (apartado 1), la especificación de la información que han de contener embalajes, envases, etiquetado, prospectos y fichas técnicas (apartado 3) y la determinación de las especialidades que pueden ser objeto de publicidad (apartado 8).

- El art. 23 del Real Decreto 767/1993, de 21 de mayo, por el que se regula la evaluación, autorización, registro y condiciones de dispensación de especialidades farmacéuticas y otros medicamentos de uso humano fabricados industrialmente (BOE, 2 de julio), establece las condiciones que ha de reunir la resolución de autorización sanitaria con especial mención a la ficha técnica, prospecto y etiquetado.

- El art. 3.1 del Real Decreto 2236/1993, de 17 de diciembre, por el que se regula el Etiquetado y el Prospecto de los medicamentos de uso humano (BOE, 18 febrero 1994) estipula que "los textos y demás características del etiquetado y del prospecto forman parte de la autorización de las especialidades farmacéuticas y otros medicamentos de uso humano fabricados industrialmente".

b) Fase de comercialización. Durante la comercialización debe proseguir la tarea informativa, incluso a cargo del fabricante. La Directiva 92/28/CEE del Consejo, de 31 de marzo de 1992, relativa a la publicidad de los medicamentos para uso humano (DOCE L 113/1992, de 30 de abril), dispone que "el titular de la autorización de puesta en el mercado del producto deberá crear dentro de su empresa un servicio científico encargado de la información relativa a los medicamentos que ponga en el mercado" (art. 13.1).

En nuestra normativa interna disponemos asimismo de muestras de esta preocupación por el control post-venta de la información del medicamento:

- El art. 14 del Estatuto de la Agencia, que encomienda a la Subdirección General de Seguridad de Medicamentos la recepción, valoración, procesamiento e información sobre sospechas de reacciones adversas (apartado g) y la identificación, evaluación y 
prevención de los riesgos asociados a la utilización de medicamentos de uso humano ya comercializados (apartado $\tilde{\mathrm{n}}$ ).

- el art. 33 de la Ley 25/1990 dicta normas sobre actualización del expediente y que obliga, por tanto, a la puesta al día de la información al consumidor.

- el art. 5.9 del R.D. 520/1999 atribuye a la Agencia del Medicamento la función de "proceder a la renovación, actualización, revisión o adecuación de las autorizaciones y registros de medicamentos de uso humano y veterinario ya comercializados, así como de sus controles técnicos".

- el art. 44.11 del R.D. 767/1993, sobre necesidad de autorización administrativa para las modificaciones en la información del etiquetado y del prospecto.

La Administración, como queda descrito, tiene encomendada una labor de vigilancia e inspección (farmacovigilancia) amén de la competencia autorizatoria de los productos farmacéuticos. El incumplimiento de tales deberes -la llamada "inactividad funcional"-, y los daños que ello origine, pueden dar lugar a responsabilidad patrimonial (12).

En conclusión, para que exista responsabilidad administrativa por omisión del deber de vigilancia/inspección es preciso que la falta de actividad administrativa debida produzca un perjuicio (13), lo que exigirá la verificación de la relación causal en un doble plano: entre la actuación inadecuada de la empresa y el daño por el uso del producto y entre la omisión administrativa y el perjuicio. O lo que es igual, habrá que probar que la no interferencia del primer nexo causal por parte de la Administración, que estaba obligada a ello (mediante la labor inspectora) hizo posible la materialización del perjuicio.

Hasta aquí hemos descrito, a grandes rasgos, un conjunto -ciertamente ampliode eventuales responsabilidades a que puede dar origen el tratamiento con medicación antidepresiva, pero como ya anunciábamos, será en sede de responsabilidad empresarial en donde concentraremos nuestra atención, y más específicamente en el deber de información sobre los productos farmacéuticos, auténtico punctum dolens de la cuestión, al menos a la vista de las noticias a las que hice referencia en nota 2.

\section{El deber de información sobre sus productos de las empresas farmacéuticas.}

\subsection{Estados Unidos.}

El American Law Institute, entidad que tiene entre sus fines confesados la clarificación, simplificación y adaptación a las necesidades sociales de la legislación norteamericana ha elaborado dos normas clave en esta materia. La virtualidad de dichas normas es que, aunque carezcan de respaldo legal alguno -no son normas jurídicas al no emanar de ninguno de los poderes que tienen atribuida tal función- han servido de referente para las legislaciones de la mayor parte de los Estados (Codes y Statutes) y han recibido una incuestionable acogida en el foro.

La Sección 402 A de la Restatement (Second) of Torts, fue la primera de dichas normas. Elaborada en 1965, establece un sistema de responsabilidad objetiva (sin culpa) que tiene dos excepciones consagradas jurisprudencialmente: 
- Que se trate de productos inevitablemente peligrosos (unavoidably unsafe products), es decir que sean productos -como los fármacos lo son en gran parte- que puestos en circulación en un estadio de conocimientos científicos dado, es imposible prever en dicho momento determinados riesgos. Son los llamados riesgos del desarrollo. La distribución de tales fármacos se justifica por el beneficio terapéutico que, en principio, comportan. Tienen sus riesgos, sí, pero no son irrazonablemente peligrosos (unreasonably dangerous). El original régimen de responsabilidad objetiva instaurado por la Restatement hizo aguas a raíz de dos decisiones que dieron un vuelco a la doctrina hasta entonces vigente, los casos Feldman v. Lederle Lab., 479 A. 2 d 374 (N.J. 1984) y Brown v. Superior Court, 751, P. 2d 470 (Cal. 1988). En ambos, se consagró la doctrina de que era ilógico hacer responder a las compañías farmacéuticas (y a la industria en general) por daños que no hubieran podido preverse. Es decir, la previsibilidad ("foreseeability") se consagró como requisito sine qua non de la responsabilidad por productos defectuosos (14).

- Que se cumplan con los deberes de advertencia. Aunque es cierto que el texto de la Restatement de 1965 no aludía expresamente a dichos deberes, ninguna duda cabe de que los tribunales entendían tal deber comprendido entre las obligaciones de la industria farmacéutica, si pretendía exonerarse de responsabilidad (objetiva).

En abril de 1997, el Instituto elaboró la Restatement (Third) of Torts mucho más detallada en lo que a información sobre productos se refiere (15). Parte de la distinción entre productos especiales (medicamentos y aparatos médicos) y no especiales (los demás). A estos últimos les es de aplicación lo dispuesto en las Secciones 1 y 2 de la Restatement (Third). A los primeros les dedica dos secciones (la 6 relativa a New Design and Warnings Standards for Prescription Products y la 10 que lleva la rúbrica Post-Sale Duty to Warn). Lo que se pretende con la nueva Restatement es afrontar cuestiones inadecuadamente resueltas en la anterior Restatement (Second), como los defectos de diseño o el fallo en el deber de advertencia -dos de las principales claves del caso Tobin, precisamente-. Esta norma, que como ya dijimos, diferencia tres tipos de defectos (de producción, de diseño y de información) y dos tipos de responsabilidad (objetiva para el primero y culpabilística para los otros dos), establece un deber de información sobre los productos en dos momentos:

- En el momento de puesta en circulación. En el caso de los productos farmacéuticos, regulados en la subsección 6 c) de la nueva Restatement, surge la responsabilidad por defectuosa información en las instrucciones o advertencias cuando pudiendo reducirse los riesgos de daño no se suministran aquellas bien al intermediario bien al propio paciente, según quien esté en mejor posición de reducir los mismos. Se tiene en cuenta, tanto al facultativo que como intermediario experto ("learned intermediary") (16) suele estar bien situado para intervenir reduciendo riesgos, como a otros posibles intermediarios suministradores de cuidados sanitarios ("other health care providers") que no posean el status médico, pero que se encuentren en la misma posición de estar en disposición de reducir eventuales riesgos. 
La Restatement (Third) of Torts, pone especial énfasis en el alcance y contenido de las advertencias que han de acompañar a los productos y servicios sanitarios, lo que ya venía siendo objeto de un importante debate académico. La nueva Restatement aborda y clarifica las discutidas y difusas lindes entre responsabilidad objetiva y culpabilística. Si en el caso de la subsección 6 a) [y por remisión 2 a)] (defectos de producción) es incuestionable la introducción de un standard de responsabilidad objetiva, en el caso de las subsecciones b) y c) de la sección 2 (defectos de diseño o defectuosas instrucciones o advertencias para productos en general) y c) y d) de la sección 6 (para fármacos y servicios sanitarios, en particular) es patente la introducción de un inequívoco elemento de subjetividad. Lo que ha de concurrir en estos dos últimos supuestos -para poder derivar responsabilidad- es la negligencia del fabricante: en caso del defectuoso diseño le es exigible una "reasonable alternative design" (para productos en general) y unas características de "reasonable" y "foreseeable" para fármacos; en el caso de la defectuosa instrucción o advertencia se le requiere "the provision of reasonable instructions or warnings". Se introduce, por tanto, el elemento culpabilístico, o dicho en otros términos, previsibilidad ("foreseeability") y razonabilidad ("reasonableness") serán los dos elementos en torno a los que se configura la responsabilidad en estas dos modalidades de actuación defectuosa (17). - En el momento post-venta. La Sección 10 de la Restatement (Third) of Torts (1997) se refiere al deber de advertencia subsiguiente a la venta del producto, entendiendo que aquella es exigible cuando a) es conocida o conocible la existencia de un sustancial riesgo de daño para personas o bienes, b) los afectados pueden ser identificados, c) la advertencia puede ser practicada y d) el riesgo de daño es de tal entidad como para justificar el deber de advertir. Con esta norma la nueva Restatement se hace recipiendaria de una doctrina que ya venía siendo aplicada por los tribunales norteamericanos y que exigía de los fabricantes una continuidad en su deber de información acorde con los progresos y descubrimientos científicos en relación con los riesgos de los productos elaborados y puestos en circulación, descubrimientos de los que dan noticia tanto la literatura científica como otros medios de comunicación (18) y cuyos principales destinatarios serán, por lo general, los médicos.

Descrita, a nivel teórico la construcción norteamericana sobre responsabilidad por productos defectuosos, veamos como se aplica la misma en un caso -que ya advierto- aún está inacabado -por la previsible apelación que seguirá a la sentencia dictada en la Corte de Distrito de Wyoming-. Me refiero al caso Tobin v. SmithKline Beecham.

El Sr. Donald Schell, de 60 años de edad y residente en la localidad de Gillette (Wyoming, USA), acudió a consulta médica el día 11 de febrero de 1998 en demanda de un tratamiento para su cuadro de "ansiedad, stress y posible depresión". Su médico de cabecera (family physician), le prescribió el fármaco Paxil, facilitándole una muestra del producto. Dos días más tarde, entre el 12 y el 13 de febrero, y "encontrándose bajo la influencia del Paxil”, según relata la demanda, Donald Schell disparó y acabó con la vida de su esposa Rita Charlotte, su hija Deborah Marie y su nieta de nueve meses Alyssa. Tras la masacre, Donald se suicidó con el mismo arma homicida. La investigación policial constató que se había tratado de un múltiple homicidio seguido de suicidio. 
Timothy John Tobin -viudo de Deborah Marie y padre de Alyssa- y Neva Kay Hardy -hermana de Rita y cuñada, por tanto, de Donald Schell- interpusieron una demanda contra la empresa farmacéutica SmithKline Beecham (que tras fusionarse con Glaxo Wellcome dio lugar a GlaxoSmithKline). La demanda se basó en que el medicamento prescrito (Paxil), es un fármaco del género de los inhibidores de la recaptación de la serotorina (SSRI, "selective serotonin reuptake inhibitors") de los que la industria farmacéutica tiene conocimiento, a través de informes publicados al menos desde febrero de 1990 (19), de que pueden generar un indeseable efecto de violencia contra terceros o episodios suicidas. A pesar de ello, indicó la demanda, SmithKline no investigó ni analizó los potenciales efectos suicidógenos o violentos del fármaco, ni tampoco advirtió a los pacientes y profesionales sanitarios de tan adversas consecuencias. Por el contrario, la industria citada llevó a cabo una agresiva campaña divulgativa del producto entre los médicos de atención primaria, personal no especializado ni con formación cualificada en "bioquímica cerebral o en conducta humana".

La acción civil exigía responsabilidades a la industria farmacéutica reseñada al considerarse causas de los decesos tanto el defecto en el diseño del fármaco como la inadecuada promoción del producto. Se estimó, además, que la conducta de la industria fue irrazonable o negligente al no investigar ni analizar los potenciales efectos violentos o suicidógenos. Así quedó planteado el litigio ante un jurado bajo la presidencia del juez William C. Beaman en la Corte de Distrito de Wyoming.

Uno de los momentos decisivos del juicio fue el rechazo por Auto (Order) del juez Beaman el 8 de mayo de 2001 de la pretensión de la empresa demandada de que fuera rechazado el testimonio de dos expertos de la parte demandante, los Dres. Healy y Maltsburger. En dicho documento Auto -34 páginas- el juez Beaman rechaza la petición en base a la importancia que tiene el testimonio de los mismos para el caso y aprovecha para detallar la amplísima literatura científica sobre la relación entre tratamiento farmacológico antidepresivo y el suicidio/homicidio.

El 6 de junio de 2001 el Jurado emitió un veredicto considerando: $1^{\circ}$. Que el fármaco Paxil puede provocar una acción suicida u homicida, $2^{\circ}$. Que en el caso concreto causó los homicidios y el suicidio reseñados, y $3^{\circ}$. Que la proporción de culpa fue de un $80 \%$ para SmithKline Beecham Corporation y de un 20\% para Donald Schell. En consecuencia, el juez Beaman condenó al pago de una indemnización de 8.000.000 dólares, de los que 6.400.000 correspondían a la empresa farmacéutica.

Las conclusiones del caso Tobin podrían sintetizarse del siguiente modo:

1. La regulación de la responsabilidad por daños provocados por productos defectuosos en USA tiene un origen contractualista, es sistema objetivo después y, finalmente [en la Restatement (Third)] acoge los dos tipos de responsabilidad: objetiva para los defectos de producción y culpabilística para defectos de diseño e inadecuación de las instrucciones y advertencias.

2. La demanda en el caso Tobin se basa en criterios culpabilísticos ("defendant's conduct is unreasonable, or negligent", "negligent failure to warn and negligent 
misrepresentations"), lo que es coherente con una línea jurisprudencial ya consolidada y formalmente reconocida a partir de la Restatement (Third).

3. El nudo gordiano de la cuestión en realidad es, no tanto un fallo en el diseño -que también-, cuanto una inadecuada por inexistente advertencia de los efectos gravemente dañosos del producto Praxil (riesgo de comportamientos violentos contra sí o contra terceros). Este deber de advertencia post-venta se encuentra específicamente reconocido en la Secc. 10 de la nueva Restatement.

4. El fallo es favorable a los demandantes sobre todo por haberse probado la existencia de una extensa literatura científica demostrativa de los riesgos dañosos del producto en cuestión, pese al intento -frustrado- de la demandada de que fuera rechazado el testimonio experto de dos especialistas que acabaron ratificando aquel extremo.

5. La actitud de la demandada no advirtiendo de los riesgos y no investigando sobre los mismos fundamentan su responsabilidad.

De todos modos, los especialistas que lean estas páginas es probable que muestren su escepticismo -yo personalmente aún carente de formación al efecto comparto esa falta de convencimiento- en relación a dos extremos: a) Corrección del diagnóstico (lo que básicamente remite a la cuestión de si fue acertado -téngase presente que el facultativo no era especialista en este área- y si el estado depresivo no encubría otra dolencia psíquica principal y b) La sorprendente rapidez de los efectos terapéuticos (adversos), prácticamente horas (20). A los especialistas dejo estas consideraciones.

\subsection{Unión Europea-España.}

En la CEE la información del consumidor aparece como una de las primeras preocupaciones del Programa Preliminar aprobado por el Consejo de Ministros de 14 de abril de 1975 (un segundo programa fue aprobado por Resolución de 19 de mayo de 1981), estableciéndose el defecto de información como fuente de responsabilidad en la Directiva 85/374/CEE, de 25 de julio. Posteriormente un conjunto de Directivas establecen el marco de un uso racional del medicamento (21).

A nivel interno, nuestra Constitución, en el art. 51 encomienda a los poderes públicos "la defensa de los consumidores y usuarios mediante procedimientos eficaces, la seguridad, la salud y los legítimos intereses económicos de los mismos", a cuyos efectos "promoverán la información y la educación de los consumidores y usuarios". Más específicamente el art. 2.1 de la Ley 26/1984, de 19 de julio, General para la defensa de Consumidores y Usuarios reconoce el derecho básico de aquellos a "la información correcta sobre los diferentes productos o servicios".

El desarrollo legal y reglamentario de tal derecho, con especial mención a los productos medicamentosos, viene dado por: la Ley 26/1984, 19 julio, General para la defensa de los consumidores y usuarios (arts. 5.2.k y 13-17), la Ley 34/1988, 11 noviembre, General de Publicidad (art. 8), la Ley 25/1990, 20 diciembre, del medicamento (arts. 10.1.d, 19 y 51.5 a 9 y 11) y los Reales Decretos 2236/1993 y 1416/1994 (22). 

destinatarios:

La información sobre productos farmacéuticos de uso humano tiene tres

- Los profesionales sanitarios, los cuales han de ser "conveniente informados" (art. 5.2.k LGDCU), siendo el instrumento básico de dicha información la llamada “ficha técnica”, la cual conforme a lo dispuesto en el art. 19.5 Ley 25/1990 “ resumirá la información científica esencial sobre la especialidad farmacéutica a que se refiere, y será difundida a los médicos y farmacéuticos en ejercicio y, en su caso, a los veterinarios en ejercicio, por el titular de la autorización, antes de la comercialización de la especialidad farmacéutica. La ficha técnica se ajustará a un modelo uniforme, y en ella constarán datos suficientes sobre identificación de la especialidad y su titular, así como la información que requiera una terapéutica y atención farmacéutica correcta, de acuerdo con los estudios que avalan su autorización. A la ficha técnica acompañará, preceptivamente, información actualizada del precio de la especialidad, y, cuando sea posible, la estimación del coste del tratamiento".

- Los consumidores, respecto a quienes los productos y servicios han de contener las "instrucciones o indicaciones para su correcto uso o consumo, advertencias y riesgos previsibles" (art. 13.1.f LGDCU), siendo el instrumento de información fundamental el prospecto ("información escrita dirigida al consumidor o usuario, que acompaña al medicamento", art. 2.g RD 2236/1993), y que conforme a lo indicado en el art. 19.4 Ley 25/1990, "proporcionará a los pacientes información suficiente sobre la identificación de la especialidad y su titular e instrucciones para su administración, empleo y conservación, así como sobre los efectos adversos, interaciones, contraindicaciones y otros datos que se determinen reglamentariamente con el fin de promover su más correcto uso y la observancia del tratamiento prescrito, así como las medidas a adoptar en caso de intoxicación".

- Público en general (23). Al que va dirigida la publicidad genérica del producto farmacéutico (24). Corresponde al Ministerio de Sanidad y Consumo (art. 31.5, 7 y 9 Ley 25/1990) determinar qué especialidades farmacéuticas pueden ser objeto de publicidad, las cuales deberán, en caso de autorización, cumplir unos determinados requisitos (art. 31.6 Ley 25/1990 y desarrollo por R.D. 1416/1994).

La información que se facilite ha de coherente entre sí (25) y, además, congruente en un doble sentido: a) Con los conocimientos científicos en el momento de la comercialización: "La información del prospecto y la ficha técnica, especialmente la que se refiere a indicaciones, contraindicaciones, efectos adversos y precauciones particulares en su empleo, deberá ser congruente con los resultados de los estudios farmacológicos a que se refieren los artículos 12 y 13 y con el estado presente de los conocimientos científicos" (art. 19.7 primer inciso Ley 25/1990) y b) Con los conocimientos adquiridos con posterioridad: “También deberán reflejar la experiencia adquirida con la especialidad farmacéutica desde su comercialización" (art.19.7 segundo inciso Ley 25/1990).

Desde luego, la determinación concreta del contenido específico que en cada caso debe contener prospecto y ficha técnica remite a un análisis casuístico. Pero, en general, la información "apropiada" (E.M. Ley 25/1990) y "precisa" (art. 10.1.d del 
mismo texto legal) tienen por finalidad proporcionar los datos para un correcto uso del producto en cuestión (26). Si esto es así, y teniendo en cuenta que el común de los usuarios/pacientes carece de una formación sanitaria medianamente aceptable a los presentes efectos, parece lógico que la información sobre riesgos recaiga de modo muy especial sobre el otro destinatario, el facultativo que prescribe el medicamento. Pero a este nivel, tampoco todo facultativo tiene igual formación para interpretar las indicaciones del producto. En general, no es descabellado afirmar que el médico especialista tendrá -o cuando menos deberá tener- unos mayores conocimientos de los fármacos empleados en su especialidad.

\section{La responsabilidad derivada de los incumplimientos empresariales.}

Ya vimos (supra) el sistema de responsabilidad (sistemas, mejor diríamos) vigente en Estados Unidos. Corresponde ahora trasladar nuestra atención a España.

Con anterioridad a la LGDCU la protección de los consumidores y usuarios tenía su asiento en las reglas generales sobre responsabilidad contractual (arts. 1101 a 1107 y 1124 CC) y extracontractual (art. 1902 CC). La LGDCU introdujo un régimen de responsabilidad en su Capítulo VIII, que tiene sus referentes en el Convenio Europeo sobre la responsabilidad derivada de los productos en caso de lesiones corporales o de muerte, aprobado por el Consejo de Europa en Estrasburgo el 27 de enero de 1977 y el Proyecto de Directiva de la C.E.E. presentado por la Comisión al Consejo de Ministros el 9 de septiembre de 1976. El sistema instaurado, y así se desprende de su art. 27, contempla todo tipo de daños y un régimen de responsabilidad objetiva. Con posterioridad, la Directiva 85/374/CEE, de 25 de julio reguló la responsabilidad por productos defectuosos, y la Ley 22/1994, de 6 de julio trasladó a nuestro derecho interno dicha Directiva, optándose por elaborar una ley especial "dado que ni el ámbito subjetivo de tutela ni el objetivo que contempla la Directiva coinciden con los de la Ley 26/1984, de 19 de julio, General para la Defensa de los Consumidores y Usuarios" (E.M.). El nuevo régimen, sigue diciendo la E.M., "establece un régimen de responsabilidad objetiva, aunque no absoluta, permitiendo al fabricante exonerarse de responsabilidad en los supuestos que se enumeran" (27).

En el caso de productos medicamentosos defectuosos cabe plantear cuál es el régimen jurídico aplicable. Respecto a los defectos ya existentes con anterioridad a la puesta en circulación no hay duda que es de plena aplicación la Ley 22/1994. Y respecto a los defectos que no fueron conocidos en su día, dado el estado de los conocimientos científicos, y que provocan sus daños después de la puesta en circulación, la duda reside en si es aplicable la regulación especial de la Ley 22/1994 o el régimen general del art. 1902 CC. Ha de tenerse en cuenta lo dispuesto en el art. 6.3 Ley 22/1994 y, en consecuencia, no se produce la exoneración por defecto existente "en el momento de la puesta en circulación" y el régimen jurídico aplicable sería un continuum que se residenciaría en la citada Ley 22/1994, cualquiera que fuera el momento de la cognoscibilidad de los defectos. 
Según el art. 3.1 de la Ley 22/1994, de 6 de julio, producto defectuoso es "aquél que no ofrezca la seguridad que cabría legítimamente esperar". La noción de producto defectuoso (28) aparece ligada al momento de "puesta en circulación", pues como señala ALCOVER "el acto del fabricante relevante a los efectos de la responsabilidad civil de productos no es propiamente el de fabricación del producto defectuoso, sino el de su puesta en circulación" (29), pudiendo definirse esta como "acto voluntario del fabricante al que se le puede conectar el resultado dañoso" (30). Esta noción también aparece ligada a la idea de peligro. Hasta el punto de que pudiéramos afirmar que la Ley 22/1994 no se refiere ni al defecto sin peligro, ni al peligro sin defecto. No se refiere al defecto carente de peligro ya que sólo se considera "producto defectuoso aquél que no ofrezca la seguridad que cabría legítimamente esperar" (art. 3.1). Y no se refiere tampoco al peligro sin defecto ya que "los fabricantes y los importadores serán responsables, conforme a lo dispuesto en esta Ley, de los daños causados por los defectos de los productos" (art. 1) y no por el mero peligro.

La cuestión que aquí particularmente interesa es el papel que desempeñan los llamados "riesgos de desarrollo" (31). En términos generales, se exonera de responsabilidad cuando el "estado de los conocimientos científicos y técnicos existentes en el momento de la puesta en circulación no permitía apreciar la existencia del defecto" (6.1.e Ley 22/1994). De ello se derivan las siguientes consecuencias (32): a) La carga de estar al corriente de los conocimientos científicos y técnicos incumbe exclusivamente al productor; b) El deber del productor de no distribuir los productos acabados y almacenados cuando se detecte la existencia de defectos a la vista de los avances existentes en el momento de puesta en circulación y c) El deber de advertencia del productor respecto a los consumidores cuando los avances científicos tienen lugar ya distribuido el producto aunque sin llegar a la cadena de distribución.

Obsérvese como en nuestro ordenamiento se diferencian - al igual que sucede en EE.UU., aunque con diferentes consecuencias- productos de baja y alta calidad social. Para los primeros rige la regla de exoneración de responsabilidad cuando el defecto no pudo apreciarse en el momento de puesta en circulación dado el estado de los conocimientos científicos y técnicos existentes. Para los segundos (medicamentos y alimentos) no es de aplicación, por el contrario, la regla de exoneración de responsabilidad (art. 6.3 Ley 22/1994).

Incuestionablemente, una mala administración medicamentosa puede provenir de una deficiente información sobre el producto. Por tanto, los fármacos, al igual que otros productos potencialmente peligrosos, han de ir acompañados de una información adecuada ya que, como indicara la STS 1a, 3.12.1997 (EDE 1997/9849), "la acción efectuada por la empresa recurrente de poner en circulación un producto evidentemente peligroso sin haber cumplido con un deber de información adecuado implica responsabilidades".

En realidad los defectos de la información son de dos tipos: puede tratarse de un defecto en la información precontractual, es decir un defecto en la información que lo que persigue es la protección del consentimiento del consumidor (33), o puede ser un 
defecto en la información contractual que se proyecta en el uso del producto. Pero en el caso de los medicamentos parece pertinente alguna matización. Cuando se trata de un producto en general la información "precontractual" pretende facilitar la configuración del consentimiento del consumidor; en el caso de un medicamento no parece que esto sea así, al menos directamente. No es el paciente el que -normalmente y a salvo del extendido y peligroso fenómeno de "automedicación"- consiente directamente sobre el producto concreto, sino que el paciente acude al facultativo precisamente para que le prescriba un tratamiento. El paciente, podríamos decir, "delega" en el médico la decisión (opción) sobre un medicamento en concreto (34).

Las especialidades farmacéuticas han de contener indicaciones sobre los "efectos adversos" (art. 5.2.k LGDCU) y las "instrucciones o indicaciones para su correcto uso o consumo, advertencias y riesgos previsibles" (art. 13.1.f LGDCU). De lo contrario se incurre en responsabilidad. Vigente la LGDCU dicha responsabilidad se especifica con mayor concreción, y así los consumidores "tienen derecho a ser indemnizados por los daños y perjuicios demostrados que el consumo de bienes o la utilización de productos o servicios les irroguen salvo que aquellos daños y perjuicios estén causados por su culpa exclusiva o por la de las personas de las que deba responder civilmente" (Art. 25 LGDCU), ya que "las acciones u omisiones de quienes producen, importan, suministran o facilitan productos o servicios a los consumidores o usuarios, determinantes de daños o perjuicios a los mismos, darán lugar a la responsabilidad de aquéllos, a menos que conste o se acredite que se han cumplido debidamente las exigencias y requisitos reglamentariamente establecidos y los demás cuidados y diligencias que exige la naturaleza del producto, servicio o actividad" (art. 26 LGDCU, y en relación con ello el art. 27 del mismo texto legal). Ninguna duda debe haber, pues, de que el fabricante es responsable de las omisiones informativas (35). El distribuidor -vendedores o suministradores de productos- es también responsable (art. 27.1.a LGDCU) aunque solo de modo subsidiario en defecto de los fabricantes cuando estos no puedan ser localizados (36). La responsabilidad es particularmente intensa en las especialidades farmacéuticas al considerarse productos que "incluyen necesariamente la garantía de niveles determinados de pureza, eficacia o seguridad, en condiciones objetivas de determinación y supongan controles técnicos, profesionales o sistemáticos de calidad, hasta llegar en debidas condiciones al consumidor o usuario" (art. 28 LGDCU).

Interesa reiterar el dato de que en los medicamentos, el que no pueda apreciarse la existencia del defecto según el estado de los conocimientos científicos y técnicos, no es causa de exoneración de responsabilidad (art. 6.3 en relación al 6.1.e), con lo que puede darse el caso de que el medicamento provoque reacciones adversas desconocidas en el momento de la puesta en circulación pero verificables tras su comercialización tras los estudios empíricos pertinentes. El defecto era preexistente (art. 6.1.b a sensu contrario) aunque desconocido según el estado de los conocimientos científicos del momento de puesta en circulación. En tal caso habrá responsabilidad. Circunstancia esta de especial interés ya que, precisamente, los productos que se encuentran más afectados por los riesgos del desarrollo son los medicamentos (y los alimentos). 


\section{A modo de conclusiones.}

1. Ante un daño hipotéticamente producido por un producto medicamentoso defectuoso (por producción, diseño o por falta de adecuadas instrucciones y/o advertencias) debe probarse el nexo causal entre el defecto y el daño producido. El caso Tobin cegado por su propia espectacularidad (masacre de toda una familia y condena de una importante compañía farmacéutica) deja latentes -hasta donde yo llego- algunas dudas: a) un diagnóstico por lo menos discutible, por su exteriorización fenoménica y b) unos efectos terapéuticos cuando menos sorprendentes, por inmediatos.

2. En los casos psiquiátricos, el margen de inexactitud diagnóstica e incertidumbre pronóstica no son desdeñables (37). A ello se une la pluralidad de efectos -en ocasiones difícilmente adivinables- de los productos medicamentosos. Siendo incuestionable la existencia de un margen de error, las actuaciones profesionales deben ser juzgadas con rigor y simultánea prudencia, lo que -en ningún caso- justifica errores inexcusables o imprudencias notorias.

3. Las legislaciones norteamericana, europea y española imponen al fabricante de productos farmacéuticos el deber de informar de los efectos indeseables de los productos que comercializan. Junto al aspecto benéfico de los avances científicos (el desarrollo), existe un inevitable peaje a pagar (riesgos) y un contrapunto imprescindible (la información). Este deber de advertencia se extiende desde el momento de la puesta en circulación hasta el período de comercialización si, durante este último, los avances científicos permiten adivinar la existencia de efectos colaterales hasta entonces no previstos.

4. La Administración tiene la obligación de ejercer sus labores de inspección y farmacovigilancia, sin perjuicio de que pueda imputársele la responsabilidad patrimonial derivada de la omisión de aquellos deberes.

5. El facultativo actuante ha de ajustar su intervención al nivel de capacitación que en cada caso corresponda, pudiendo derivarse -en caso contrario- las responsabilidades deontológicas, civiles, penales y/o administrativas que procedan. La intervención de personal especializado en el manejo de fármacos sensibles parece aconsejable.

*Funcionario Cuerpo Especial II.PP.

Colaborador del Área de Derecho Administrativo de la Universidad de Alicante

Área de Derecho Administrativo/Departamento de Estudios Jurídicos del Estado de la Universidad de Alicante.

Hospital Psiquiátrico Penitenciario de Alicante.

luisfbarrios@eresmas.com

Apartado de Correos 67503080 Alicante

Fecha de recepción: 4-VII-01 


\section{BIBLIOGRAFÍA}

(1) Lejos quedan los tiempos en que Livia aconsejaba a su marido el emperador Augusto: "Haz como los médicos, que cuando una medicina no sirve emplean la contraria". Montaigne, M. E., Ensayos, Libro I, XXIII; Barcelona, Orbis, 1984, Vol. I, p. 85. Como distamos mucho de compartir la militante posición antigalénica del ilustre -y frecuentemente enfermo- Moliére cuando ponía en boca de Beraldo: "Saben muchas cosas [los médicos]. La mayoría de ellos saben sus buenas humanidades; saben también hablar en pomposo latín y designar, en griego, los nombres de todas las enfermedades, definirlas y clasificarlas. Ahora bien, en lo tocante al modo de curarlas, de eso no saben absolutamente nada"; Moliére, J. B. P., "El enfermo imaginario", en Moliére: Comedias, Barcelona, El Círculo de Lectores, 1973, p. 572.

(2) Me refiero al caso Tobin v. SmithKline Beecham, publicado en el New York Times (http://www.nytimes.com) el 8.6.2001 y el caso de Andrea Pia Yates, publicado en el Houston Chronicle (http://www.chron.com) el 21.6.2001. Del primero hablaré después. Del segundo poco sabemos aún: una mujer, que al parecer venía siendo tratada de una depresión post-partum, es detenida por la policía acusada de acabar con la vida de sus cinco hijos en Houston (Texas).

(3) Cfr. Augusto León, C., Ética en Medicina, Barcelona, 1973, p. 158 y Gómez Pavón, P., Tratamiento médicos: su responsabilidad penal y civil, Barcelona, Bosch, 1997, p. 334.

(4) Cfr. Herranz, G., Comentarios al Código de Ética Deontología Médica, Pamplona, EUNSA, 1995, pp. 109-110.

(5) Santos Briz, J., "La responsabilidad civil de los médicos en el Derecho español", Revista de Derecho Privado, jul.-ago. 1984, p. 659 y Alonso Pérez, M., "La relación médico-enfermo, presupuesto de responsabilidad civil (en torno a la «lex artis»), en Moreno Martínez, J.A.: Perfiles de la responsabilidad civil en el nuevo milenio, Dykinson, 2000, pp. 33 y ss.

(6) Berdugo Gómez de la Torre, I. et al., Lecciones de Derecho Penal. Parte General, Barcelona, Praxis, 1999, p. 205.

(7) Cervantes, M., El licenciado Vidriera, Madrid, Metyel, 1996, p. 62. "Récipe" (del latín recipiendum, que ha de ser recibido) fue término frecuente en el encabezamiento de las recetas.

(8) Me remito por ello a la bibliografía específica sobre el tema. Por ejemplo: Ataz López, J., Los médicos y la responsabilidad civil, Madrid, Montecorvo, 1985, pp. 347-375; Fernández Costales, J., Responsabilidad civil médica y hospitalaria, Madrid, La Ley, 1987, en especial pp. 181 y ss.; Alonso Olea, M., "Responsabilidad del hospital por el acto del médico", Revista Española de Derecho del Trabajo, 1996, núm. 79, pp. 777 y ss.

(9) Rojo yFernández Río, A., La responsabilidad civil del fabricante, Bolonia, 1974, pp. 187 y ss.

(10) La New Restatement diferencia tres supuestos de responsabilidad por defecto en los productos: el defecto en la producción (manufacturing defect), el defecto de diseño (defective in design) y el daño derivado de defectuosas instrucciones o advertencias (defective because of inadequate instructions or warnings). Esta diferenciación ha sido aplaudida por la doctrina y la jurisprudencia; vid. Wagner, M. J. y Peterson, L.L.: "The New Restatement (Third) of Torts Schelter From the Product Liability Storm for Pharmaceutical Companies and Medical Device Manufacturers?", Food and Drug Law Journal, 1998, Vol. 53, p. 241.

(11) En realidad, la introducción de este elemento culpabilístico en absoluto es nueva. Tanto la doctrina como la jurisprudencia venían ya considerando la relevancia de un importante 
elemento subjetivo en la responsabilidad por productos defectuosos; así Wetheimer, Ellen: "Unknowable Dangers and the Death of Strict Products Liability: The Empire Strikes Back", Univ. Cin. Legal Review, 1992, Vol. 60, pp. 1183 y ss. Pero es la primera vez en que de forma tan nítida se residencia la distinción en una norma (no legal, sino referencial como son todas las normas del American Law Institute).

(12) Gómez Puente, M., La inactividad de la Administración, Pamplona, Aranzadi, 1997, pp. $760-763$ y 812 y ss.

(13) Gómez Puente, M., op. cit., p. 814.

(14) Así en Carlin v. Superior Court, 920 P. 2d 1347 (Cal. 1996).

(15) Cfr. Wagner, M. J. y Peterson, L.L., op. cit., pp. 225-242; OWEN, D., "Products Liability Law Restated”, South Carolina Law Review, 1998, Vol. 49, pp. 273-293 y Dreier, W.A., “Manufacturers' Liability for Drugs and Medical Devices Under the Restatement (Third) of Torts: Products Liability", Seton Hall Law Review, 1999, Vol. 30, pp. 258-264.

(16) Sobre esta materia la Restatement (Third) introduce algunas novedades a la tradicionalmente conocida como "teoría del intermediario experto" ("learned intermediary doctrine") ya perfilada en Reyes v. Wyeth Labs., 498 F. 2d 1264, 1276 (5th Cir. 1974).

(17) La introducción de este elemento culpabilístico en absoluto es nueva, como ya he advertido. Tanto la doctrina como la jurisprudencia venían ya considerando la relevancia de un importante elemento subjetivo en la responsabilidad por productos defectuosos. Así Wetheimer, E., "Unknowable Dangers and the Death of Strict Products Liability: The Empire Strikes Back", Univ. Cin. Legal Review, 1992, Vol. 60, pp. 1183 y ss.

(18) Por ejemplo en Wooderson v. Ortho Pharm. Corp., 681 P. 2d 1038, 1050-51 (Kan. 1984); Schenebeck v.Sterling Drug Inc., 423 F. 2d 919, 922 (8th Cir. 1970); Baker v. St. Agnes Hosp., 421 N.Y.S. 2d 81, 85 (1979). Sobre el relevante papel de la literatura científica en la farmacovigilancia vid. Madurga, M., La documentación y la farmacovigilancia en La farmacovigilancia en España, Instituto de Salud Carlos III, Madrid, 1992, pp. 147-167, en especial pp. 151 (ventajas e inconvenientes), 152 (directrices de las publicaciones) y 154 (funciones que desempeña).

(19) Las publicaciones científicas son incluso anteriores. En relación con la imipramina, Kielholz, P. y Battegay, R., "Behandlung depressiver Zustandsbilder, unter spezieller Berückichtigung von Tofranil, einem neuen Antidrepressivum", Schweiz. Med. Wochenschrift, 1958, Vol. 88, pp. 763-767, y en general, Grunberger, J. y Saletu, B., "Determination of pharmacodynamics of psychotropic drugs by psychometric analysis", Prog. Neuropsychopharmacol, 1980, Vol. 4, pp. 417-434 y Teicher, M., Cole, J. y Glod, C., "Emergence of intense suicidal preoccupation during fluoxetine treatment", Am. J. Psychiatry, 1990, Vol. 147, fasc. 2, pp. 207-210. Además de la abundante literatura citada por el Juez Beaman en el Auto de 8.5.2001.

(20) Con todos los avances de las nuevas generaciones de antidepresivos, parece no discutido que "aunque los antidepresivos más nuevos son mucho más seguros que sus predecesores, requieren un período de administración similar antes de que se observen los efectos terapéuticos"; Kelly, J., "Estado actual de la farmacoterapia antidepresiva", en Pichot, P (Edit), Psicofarmacología: de los mecanismos básicos a la respuesta clínica, Madrid, Aula Médica Edics., 1999, p. 296.

(21) Directiva 92/25/CEE del Consejo, relativa a la distribución al por mayor de los medicamentos de uso humano; Directiva 92/26/CEE del Consejo, relativa a la clasificación para su 
dispensación de los medicamentos de uso humano; Directiva 92/27/CEE del Consejo, relativa al etiquetado y al prospecto de los medicamentos de uso humano; Directiva 92/28/CEE del Consejo, relativa a la publicidad de los medicamentos de uso humano. Todas ellas de fecha 31.3.1992 y todas publicadas en el DOCE L 113 de 30.4.1992.

(22) R.D. 2236/1993, de 17 de diciembre, por el que se regula el etiquetado y prospecto de los medicamentos de uso humano (BOE, 18.2.1994), que desarrolla la Directiva 92/27/CEE del Consejo, de 31 de marzo de 1992, relativa al etiquetado y al prospecto de los medicamentos de uso humano, (DOCE L 113 de 30.4.1992) y R.D. 1416/1994, de 25 de junio, por el que se regula la publicidad de los medicamentos de uso humano (BOE, 29.7.1994), que desarrolla la Directiva 92/28/CEE del Consejo, de 31 de marzo de 1992, relativa a la publicidad de los medicamentos de uso humano (DOCE L 113 de 30.4.1992). El primero de los RRDD citados fue desarrollado y clarificado por Circular 29/1994 de la Dirección General de Farmacia y Productos Sanitarios.

(23) Cfr. Royo Vela, M. y Miquel Peris, S., "La publicidad como fuente de información de consumo: diferentes aproximaciones conceptuales", Estudios de Consumo, 1999, núm. 49, pp. 9-20.

(24) Rico-Pérez, F., La responsabilidad civil del farmacéutico, Madrid, Trivium, 1984, p. 243, hace una distinción entre información y publicidad, según los destinatarios. Hoy en día, considero que ambas van dirigidas a los dos colectivos: a) La información va dirigida a los profesionales (ficha técnica) pero también al público consumidor (prospecto y etiquetado) y b) La publicidad va dirigida a uno y a otro, aunque por lo común se utilizan preferentemente diferentes medios de comunicación: literatura especializada en el caso de los profesionales, medios de comunicación general para el público (solo respecto a aquellos productos en los que la publicidad es admisible).

(25) Es decir, ha de existir una correspondencia entre prospecto y ficha técnica (art. $2.1 \mathrm{RD}$ 2236/1993), pues de lo contrario podrá derivarse responsabilidad (por ejemplo en SAP Baleares (Sec. $4^{\text {aa }}$, 19.7.2000, EDE 2000/39211).

(26) Como afirma la SAP Madrid, Sec. 21ª 5.3.1999 (Pte. Fernández Benito): “esa corrección o no en el uso y consumo del producto por el usuario o consumidor no puede desligarse de la información que su productor o suministrador le proporcione para su seguridad".

(27) Cfr. Bercovitz Rodríguez-Cano, R., La responsabilidad por los daños y perjuicios derivados del consumo de bienes y servicios en Estudios jurídicos sobre protección de los consumidores, Madrid, Tecnos, 1987, pp. 222-247 y Lois Caballé, É, A.I., "Una nueva solución a los accidentes causados por los defectos de los productos: la Ley 22/1994, de responsabilidad por los daños causados por productos defectuosos", Estudios de Consumo, 1998, núm. 44, pp. 21-27.

(28) Vid. Parra Lucán, M. A., “Ámbito de protección de los daños por productos (sistema y naturaleza de la responsabilidad civil previsto en la Ley 22/1994)", Iniuria,, ene.-mar. 1995, núm. 5; Solé y Feliú, J., El concepto de defecto del producto en la responsabilidad del fabricante, Valencia, Tirant lo Blanch, 1997.

(29) Alcover Garau, G., La responsabilidad civil del fabricante. Dercho Comunitario y adaptación al derecho español, Madrid, Civitas, 1990, p. 118.

(30) Cordero Cutillas, I., "La puesta en circulación en la responsabilidad civil por productos defectuosos", Estudios de Consumo, 2000, núm. 53, p. 47. 
(31) Vid. Garcia Rubio, M.P., "Los riesgos de desarrollo en la responsabilidad por daños causados por productos defectuosos. Su impacto en el derecho español", Actualidad Civil, 28 sep.-4 oct. 1998, núm. 38 .

(32) Cordero Cutillas, I., op. cit., p. 55.

(33) Cfr. Gómez Calle, E., Los deberes precontractuales de información, Madrid, La Ley, 1994.

(34) Esta delegación configura la llamada relación de agencia paciente/médico, relación que tiene dos características básicas: es asimétrica (clara desigualdad en la información de uno y otro) y es imperfecta (ya que el agente médico toma decisiones con información imperfecta -al caso me remito- sobre la efectividad de la tecnología sanitaria aplicada (en nuestro caso medicamento). Vid. PUIG, Jaume: "Innovación tecnológica y mercado sanitario: de la macroregulación a la micro-regulación”, XIV Jornadas de Economía de la Salud: Cambios en la regulación sanitaria, Barcelona, Asociación de Economía y Salud, 1995, pp. 337 y ss

(35) Vid. en este sentido Pérez García: La información en la contratación privada. En torno al deber de informar en la Ley General para la Defensa de los Consumidores y Usuarios, Madrid, 1990, p. 258.

(36) Ortí Vallejo, A., "Comentario al art. 13” en Bercovitz Rodríguez-Cano, R. Salas Hernández, J. (Coords): Comentarios a la Ley General para la Defensa de los Consumidores y Usuarios, Madrid, Civitas, 1992, p. 422.

(37) Razones de espacio me impiden extenderme sobre esta cuestión. Baste decir que es pacíficamente admitido la inexactitud e incertidumbre que rodean en una medida no desdeñable el conocimiento y la práctica psiquiátrica. Desde Hipócrates ("Sobre la medicina antigua", en Tratados hipocráticos, Madrid, Gredos, 2000, pp. 36-37) hasta Jaspers (Psicopatología General, Buenos Aires, Edit. Beta, $4^{a}$ edic., 1980, p. 952), pasando por Kräpelin ("Las manifestaciones de la locura", en Hoche, A., Kräpelin, E., y Bumke, O., Los síntomas de la locura, Madrid, Madrid, 1999, pp. 57-58). 